\title{
Colonialidad/descolonialidad de la Universidad peruana
}

\author{
César Germaná Cavero \\ Universidad Nacional Mayor de San Marcos \\ cgermanac @unmsm.edu.pe
}

\begin{abstract}
RESUMEN
El presente texto busca abrir algunas cuestiones que permitan dar cuenta de los profundos cambios que se están produciendo en la universidad peruana que está atravesando una crisis estructural. Cuando me refiero a la crisis de la universidad no aludo a las dificultades que existen dentro del sistema universitario, que son muchas. Estas son crisis superficiales y pueden ser resueltas mediante algunas reformas. La verdadera crisis es la producida por problemas que no pueden ser resueltos dentro de los marcos del sistema existente, sino que requiere de otro sistema que los solucione. La educación superior en el Perú se encuentra en esta situación. El modelo de universidad dominante en gran parte del siglo XX ha llegado a un punto de bifurcación. Ese modelo se ha erosionado y estamos en un periodo caótico de tránsito hacia otra forma de organización institucional de la producción y transmisión del saber altamente calificado. La crisis de la universidad moderna/colonial se inicia hacia fines de los años de la década de 1960 y da cuenta de su incapacidad para resolver tres grandes complejos de problemas: problemas epistemológicos, problemas institucionales y problemas de legitimidad. Examinar algunos aspectos de las alternativas que se le abren a la actual crisis de la institución universitaria es el interés del presente trabajo.
\end{abstract}

Palabras clave: Universidad, colonialidad, descolonialidad, neoliberalismo, reforma universitaria

\section{Coloniality / Decoloniality of the Peruvian university}

\begin{abstract}
This text seeks to open up some issues that will allow accounting for the deep changes that are taking place in the Peruvian university that is going through a structural crisis. When I refer to the crisis of the university, I do not mention the difficulties that are within the university system, which are many. These are shallow crises and can be resolved through some reforms. The real crisis is caused by problems that cannot be solved within the framework of the existing system, but requires another system to solve them. Higher education in Peru is in this situation. The pervasive university model in much of the twentieth century has reached a point of bifurcation. That model has eroded and we are in a chaotic period of transit towards another form of institutional organization of the production and transmission of highly qualified knowledge. The crisis of the modern / colonial university began at the end of the 60's, and reveals its inability to solve three major complex problems: epistemological problems, institutional problems and problems of legitimacy. The interest of this work is to examine some aspects of the options opening up to the current crisis of the university institution.
\end{abstract}

KeYworDs: University, coloniality, decoloniality, neoliberalism, university reform 


\section{Introducción}

Quisiera empezar seńalando que la universidad, como todo fenómeno social, está definida por la trama de relaciones sociales dentro de las cuales se desenvuelve. Estas relaciones sociales son relaciones de poder, es decir, relaciones de dominación, de explotación y de conflicto. Es posible identificar las relaciones de poder existentes en la vida social en una de las tareas centrales de la universidad moderna como es la producción y la transmisión de conocimientos, pues este quehacer no se presenta — como generalmente se piensacomo una actividad neutra, libre de valores, sino más bien atravesado por una de las formas más perniciosas de poder: la colonialidad del saber/conocer.

Si examinamos la profunda reorganización de la sociedad peruana producida en las últimas tres décadas — caracterizada por la contrarrevolución neoliberal—, podemos advertir cómo se ha venido modificando de manera sustancial los vínculos entre la universidad y la estructura de poder, tanto en cómo el poder produce y reproduce a la universidad como en el modo en que la universidad se articula con el poder. De allí que la situación y las tendencias que están ocurriendo en el conjunto del tejido social constituye el punto de partida del debate y la investigación sobre universidad, tanto en sus aspectos materiales como intersubjetivos. Los cambios que están sucediendo en la actualidad en las relaciones de poder son tan profundos y drásticos que está alterando de manera radical las relaciones entre la universidad y el conjunto de la sociedad.

En la larga historia de la universidad en el Perú —y creo que en el resto de América Latina - es posible reconocer la existencia de tres grandes poderes hegemónicos que han definido la orientación de los modelos dominantes de universidad: la Iglesia, el Estado y el mercado. La Iglesia católica orientó la universidad colonial; el Estado ha sido el garante de la universidad que surgió con el movimiento de la reforma universitaria; y el mercado constituye el horizonte dentro del cual se desenvuelve la universidad neoliberal.

\section{La universidad colonial}

Desde sus orígenes, la naturaleza de la universidad en el Perú ha sido la colonialidad. Se trataba de una universidad colonial no solamente porque fue impuesta administrativamente por el poder colonial (pues requería para su funcionamiento contar con una cédula real y una bula papal), sino, fundamentalmente, porque su función principal fue la de formar a los responsables de imponer a la población conquistada una perspectiva de conocer/saber que era considerada como la única socialmente legítima y de destruir, reprimir y marginar las que estos pueblos poseían. Su tarea fue, pues, lograr que los dominados aceptaran su inferioridad como algo natural y, así, producir y reproducir el patrón de dominación centrado en la colonialidad del poder. 
La universidad republicana no modificó la colonialidad de la institución; más bien la consolidó. Su función principal fue la de educar a las élites destinadas a ocupar posiciones de prestigio y de influencia en la estructura de poder. Sus profesores y alumnos se reclutaban dentro de la oligarquía dominante. Se trataba de una universidad elitista, pues excluía de ella a las capas medias y a las clases populares; una ideología aristocratizante y señorial orientaba sus estudios, ya que la ciencia y la técnica como actividades autónomas no habían logrado imponerse en el trabajo académico. La organización académico-administrativa, basada en las cátedras y en las facultades, determinaba una estructura jerárquica, vertical y autoritaria de la institución.

\section{La universidad moderna/colonial}

Con las luchas del movimiento de la reforma universitaria, que se inició en Córdova en 1918, se fue constituyendo en el Perú -como en el resto de América Latina, con diferentes ritmos y modalidades- la universidad moderna/colonial.

Una de las primeras reivindicaciones de las capas medias que emergen a la vida social y política del país en la década de 1920, será la democratización y la profesionalización de la universidad oligárquica/colonial. El programa de la reforma universitaria va a sistematizar los intereses de estas nuevas capas sociales y constituirá una de las banderas centrales de la lucha antioligárquica en el país. A pesar de la vaguedad y ambigüedad del movimiento, es posible señalar algunas de sus demandas principales centradas en la búsqueda de una mayor participación de las capas medias en la vida de la universidad. Este objetivo se traducirá en tres reclamos básicos: el acceso meritocrático a la educación superior, la participación de los alumnos en el gobierno de la universidad y la libertad académica y de cátedra. De este modo, la lucha por la democratización y por la autonomía universitaria buscaba la remoción de los profesores de la oligarquía que se arrogaban el control de la universidad y la apertura del claustro para lograr la incorporación de las capas medias mayoritariamente excluidas.

De otro lado, el movimiento reformista no solamente tenía por objetivo democratizar la universidad, también quería profesionalizarla. Para ello reivindica el mejoramiento de la enseñanza de determinadas carreras profesionales (medicina, ingenierías, administración) y un decidido apoyo al desarrollo científico y tecnológico que permitiera erradicar la orientación aristocratizante y seńorialista de la universidad oligárquica/ colonial.

En el Perú, el modelo reformista de universidad se va a institucionalizar en tres momentos. Entre 1946 y 1950 con el "Estatuto General de la Universidad Peruana"; entre 1960 y 1969 con la Ley 13417; y entre 1983 y 2014 con la Ley Universitaria 23733. En esos periodos se reconocen algunas de las principales demandas del movi- 
miento reformista: la organización académico-administrativa basada en departamentos y facultades, el cogobierno estudiantil, la autonomía universitaria y la gratuidad de la enseñanza. Estas medidas tienen por efecto ampliar el acceso a la universidad de las capas medias y, en este sentido, posibilitan una democratización de la composición social y del gobierno de la institución. En agosto del año 2014 se promulgó una nueva ley universitaria que, si bien mantiene algunas de los objetivos del movimiento reformista tiene una orientación privatista y tecnocrática.

Tres características principales definieron el modelo reformista de universidad: la imposición de las estructuras de saber eurocéntricas, como perspectiva hegemónica de producir conocimientos; la institucionalización del saber en estructuras académicas disciplinarias y, finalmente, el posicionamiento de las funciones de formación profesional de la mano de obra calificada y de la investigación para el capitalismo periférico y la administración pública.

En cuanto a la primera característica, las estructuras de saber/conocer eurocéntricas, estas están referidas a una perspectiva de conocimiento -una manera de percibir la realidad, de producir las preguntas y ordenar las respuestas sobre la realidad natural y social-, considerada socialmente legítima dentro del patrón de dominación moderno/ colonial. Tres supuestos básicos definen estas estructuras del saber. El primero, la epistemología cartesiana de la simplificación que, a diferencia de la aristotélica, basada en la experiencia, va de las ideas a las cosas y no de las cosas a las ideas; en la epistemología cartesiana, que busca establecer "ideas claras y distintas", donde conocer significa dividir y clasificar para después poder determinar las relaciones sistemáticas entre lo que se separó (Bachelard, 1972: cap. VI). El segundo supuesto, la tesis de las dos culturas, se refiere a la separación entre la "cultura científica" y la "cultura humanística". Mientras la "cultura científica" busca llegar a la verdad mediante el método experimental y trata sobre juicios de hecho, esto es, juicios sobre la realidad tal como supuestamente es; la "cultura humanística" se preocupa por debatir sobre los valores estéticos y éticos, como la belleza y la justicia, trata, por tanto, sobre juicios de valor, esto es, juicios sobre el deber ser (Snow, 1977; Prigogine y Stenger, 1990:123; Wallerstein, 2005a: 23-35, Cerroni, 1971: 13-23). El tercer supuesto, se refiere a la aceptación de una epistemología que establece la separación entre el sujeto y el objeto de conocimiento y cuyo corolario se impone como la neutralidad valorativa.

La segunda característica de la universidad moderna/colonial ha sido la institucionalización del conocimiento en una estructura académico-administrativa disciplinaria, donde la especialización del conocimiento es la base de la organización académica de la universidad. Por un lado, de acuerdo a la tesis de las dos culturas, se divide el saber en dos grandes áreas administrativas: las ciencias y las humanidades; de otro lado, se establecen los departamentos como unidades corporativas del ejercicio de una determinada disciplina; un conjunto de disciplinas afines constituye una facultad, y el conjunto de 
las facultades forma una universidad. La universidad aparece así como una estructura especializada de saberes, independientes unos de los otros.

La tercera característica se refiere a las funciones que cumple la universidad moderna/colonial en la sociedad periférica. La universidad reformista se orientó en dos direcciones: de un lado, se preocupó por la formación de los profesionales altamente calificados que el mercado de trabajo del capitalismo periférico requería; y, de otro lado, impulsó la investigación vinculada a satisfacer las necesidades menos complejas del proceso productivo dependiente.

\section{La crisis de la universidad moderna/colonial}

El modelo de universidad moderna/colonial entró en un periodo de crisis hacia mediados de los años 1970. Esta crisis hacía parte de la erosión del patrón de poder moderno/ colonial que había dominado el planeta en los últimos quinientos años. En este periodo el mundo de las relaciones intersubjetivas se ha comenzado a reorganizar profundamente, en particular las estructuras de saber/conocer y las instituciones que las producen y las reproducen, entre ellas, la universidad. Tres crisis plantean la necesidad de la transformación y la posibilidad de descolonialidad de la universidad.

En primer lugar, la crisis de las estructuras de saber eurocéntricas. En la segunda mitad del siglo XX se asiste a un profundo cambio en la perspectiva de producir conocimientos que va a incidir en el cuestionamiento de la hegemonía del saber eurocéntrico. A ese momento Ilya Prigogine lo puntualizó como el "fin de las certidumbres" (Prigogine, 1997). Se trata de "un momento privilegiado de la historia de la ciencia", pues el conocimiento científico se enfrenta a nuevas preguntas y a nuevos riesgos. "Asistimos a la emergencia de una ciencia — dice Prigogine — que ya no se limita a situaciones simplificadas, idealizadas, mas nos instala frente a la complejidad del mundo real, una ciencia que permite a la creatividad humana vivenciarse como la expresión singular de un rasgo fundamental común en todos los niveles de la naturaleza" (Prigogine, 1997: 13). En consecuencia, la ciencia ya no se identifica con la certidumbre: "Tanto en dinámica clásica como en física cuántica las leyes fundamentales ahora expresan posibilidades, no certidumbres" (Prigogine, 1997: 11). La "ciencia clásica" privilegió la estabilidad y el orden, eliminando la incertidumbre; en cambio, la "nueva ciencia" privilegia las fluctuaciones y la inestabilidad. En este sentido se puede afirmar que, como lo plantean Nicolis y Prigogine: "desde la década de los años sesenta, somos testigos de una revolución en las ciencias matemáticas y físicas que nos obliga a adoptar una postura completamente nueva para la descripción de la naturaleza" (Nicolis y Prigogine, 1997: 22).

Se puede señalar cuatro perspectivas de análisis que apuntan al cuestionamiento de las estructuras del saber eurocéntrico. La primera se encuentra en la epistemología de la 
complejidad y su corolario, la unificación del saber. La complejidad implica la existencia de sistemas con un gran número de elementos interactivos y que se interdefinen, para utilizar el concepto propuesto por González Casanova. Una epistemología de esta naturaleza conlleva la superación de las "disciplinas" y apunta a la unificación del saber en una orientación transdisciplinaria, perspectiva que apunta a "volverse especialista en el estudio de un problema, independientemente de que la especialización signifique manejar disciplinas que se enseñen en diferentes facultades" (González Casanova, 2005: 27).

La segunda perspectiva está dado por la teoría del caos como teoría de los sistemas alejados del equilibrio (Balandier, 1999). Según Prigogine, la ciencia clásica preocupada por el equilibrio dejó de lado el tiempo; en cambio, la nueva ciencia lo considera el elemento central de los diversos sistemas, en particular los sistemas sociales que son los más complejos, donde los procesos son irreversibles. "Si nuestro mundo tuviera que ser entendido sobre la base del modelo de los sistemas dinámicos estables no tendría nada en común con el mundo que nos rodea: sería un mundo estático y predecible, pero no estaríamos allí para formular las predicciones. En el mundo que es nuestro descubrimos fluctuaciones, bifurcaciones e inestabilidades en todos los niveles" (Prigogine, 1997: 58).

La tercera perspectiva está dada por la consideración al conocimiento como un proceso intersubjetivo. Si bien existe un mundo independiente del sujeto, el conocimiento no se produciría sin la intervención del sujeto, lo que daría lugar a un "relativismo conceptual" compatible con el "realismo de sentido común" (Putnam, 1994: 61). Al medir, modificamos lo medido. El conocimiento aparece, en consecuencia, como un producto intersubjetivo: hace parte de las relaciones simbólicas que se dan entre los sujetos. De allí que las reglas epistemológicas que establecen la verdad o falsedad de un conocimiento sean reglas sociales. Se trata de una validación intersubjetiva del saber opuesta a cualquier forma de realismo que base la verdad en una "adecuación de la cosa y de la mente" (Bourdieu, 2003: 127-148).

La cuarta perspectiva de análisis proviene de la emergencia de las estructuras de saber/conocer de los pueblos indígenas y afrodescendientes. Catherine Walsh ha señalado bien la importancia de los saberes indígenas en el mundo actual en un proyecto de descolonialidad del poder: "Entender y utilizar de esta manera el conocimiento, como hace el movimiento indígena, sugiere que su proyecto político no es simplemente político sino además epistemológico. Dentro de esta concepción y uso políticos del conocimiento se encuentra un sistema epistemológico que incorpora formas de saber y conocer, conceptos, lógicas e ideologías culturales enraizados en una experiencia y condición histórico-cultural y las relaciones de poder que también se constituyen en ellas. Es esta condición histórico-cultural y colonial (donde se representa, margina, disciplina y a veces destruye el conocimiento indígena) la que ha generado la producción de nuevos conocimientos dentro de un proyecto de descolonización, nuevos modelos de análisis, conceptualización y pensamiento que conciben el 'problema indígena' como 
un problema fundamentalmente estructural, político y económico vinculado con la hegemonía capitalista de naturaleza inter/trans/nacional (CONAIE 1994). Además, es la imbricación de lo histórico-cultural con lo nuevo la que da significado a este conocimiento político." (Walsh, 2001: 113)

En las ciencias sociales de América Latina se han desarrollado múltiples propuestas orientadas al cuestionamiento del eurocentrismo. Señaladamente importantes han sido los estudios poscoloniales y la perspectiva de análisis de la colonialidad/descolonialidad del poder.

Los estudios poscoloniales encuentran sus premisas intelectuales en las teorías posmodernas, particularmente en el posestructuralismo francés y designa el poscolonialismo como una situación histórica específica donde el sistema-mundo aparece como "un sistema de significaciones culturales" (Castro-Gómez y Grosfoguel, 2007: 16). También se puede decir, como propone Santiago Castro-Gómez (Castro-Gómez, 1998), que los estudios poscoloniales constituyen una perspectiva analítica posmoderna, pero desde las regiones subalternizadas por la modernidad europea y que es teorizada por intelectuales del Sur que viven y trabajan en las universidades del Norte. La conceptualización de los estudios poscoloniales que hace Miguel Mellino apunta en esta misma perspectiva: "se puede definir el paradigma poscolonial como un desarrollo del pensamiento posmoderno orientado a la crítica cultural y a la deconstrucción de las nociones, de las categorías y de los presupuestos de la identidad moderna occidental en sus más variadas manifestaciones" (Mellino, 2008: 51).

En una orientación epistemológica y teórica que cuestiona de manera radical el eurocentrismo de las estructuras de saber/conocer con el objeto de lograr la emancipación de los seres humanos, ha surgido, desde la década de 1990, la perspectiva de análisis de la colonialidad/descolonialidad del poder propuesta por Aníbal Quijano (Quijano, 2000 a y b; 2001 a y b; 2007; 2009; 2010). Este enfoque teóricamente innovador plantea que con la conquista, en 1492, de lo que posteriormente se va a llamar América, surgió un patrón de poder sui géneris que tiene como características la colonialidad y la modernidad. De un lado, la colonialidad en la medida en que las relaciones de poder que se establecen con la conquista están atravesadas por la idea de "raza"; esto es, la consideración de que los conquistadores se imaginaban seres humanos superiores y se autoidentificaban como "blancos", mientras que a los conquistados los miraban como humanamente inferiores y los identificaban como "indios" y "negros". La idea de “raza”, al naturalizar una relación social, como una especie de alquimia social, buscará legitimar la dominación y explotación de la población aborigen y de los esclavos africanos y será parte fundamental del mantenimiento del patrón de poder aún después de producida la independencia política de las colonias españolas y portuguesas, pues garantiza que dominadores y dominados acepten como natural la dominación. De otro lado, la modernidad, la otra cara de la colonialidad, que puede ser como la creciente 
racionalización instrumental de la vida social, donde el avance científico-tecnológico será su principal indicador.

La segunda crisis de la universidad moderna/colonial se refiere a la inviabilidad de las estructuras institucionales disciplinarias. Las nuevas ciencias — basadas en la epistemología de la complejidad, en el estudio de los sistemas alejados del equilibrio y en la intersubjetividad del conocimiento- y la emergencia de los saberes sometidos (Foucault, 2000), ya no pueden tener cabida dentro de estructuras institucionales disciplinarias. Esta contradicción hace de la crisis institucional una de las más visibles de la universidad actual pues su organización corporativa aparece como una camisa de fuerza que no permite el desarrollo de las nuevas formas de producir conocimiento.

La tercera crisis tiene que ver con la legitimidad de la universidad moderna/colonial. No existe un consenso en la sociedad que reconozca el papel central de la universidad en la producción y reproducción del conocimiento socialmente legítimo. La desconfianza se da en dos frentes. Por un lado, las nuevas exigencias que plantea el capitalismo del periodo actual, caracterizado por la necesidad de mercantilizar los conocimientos como una forma de valorizar el capital, requiere la redefinición de las funciones de la universidad. Pero el recelo frente a la universidad también proviene de la población que la universidad históricamente ha marginado. Los saberes de los colonizados fueron reprimidos y excluidos por la universidad que los consideraba ilegítimos, pues no se ajustaban al canon eurocéntrico. En consecuencia, ni los intereses de los grupos sociales dominantes ni los de los dominados se sienten representados por la universidad. En esta insatisfacción frente al rol que cumple la universidad en la sociedad se encuentra el estímulo de las fuerzas sociales que buscan reformarla.

\section{La autoritaria modernización universitaria del régimen militar}

Un primer intento de reorganizar la universidad reformista fue llevado adelante por el régimen militar del general Velasco Alvarado instaurado en 1968. Desde sus inicios el régimen militar trató de dar una respuesta a la cuestión universitaria. Así, la promulgación del Decreto Ley 17437 ("Ley de la Universidad Peruana”) de 1969, y los capítulos correspondientes de la "Ley General de Educación" (D.L.19326) de 1972, diseñan una nueva política de modernización autoritaria de la universidad que, en sus líneas principales, se mantendrá vigente hasta 1983, cuando se promulga una nueva ley universitaria.

El objetivo fundamental que se encuentra en la propuesta del régimen militar fue modernizar el sistema universitario para adecuarlo a las necesidades y exigencias del desarrollo de un proyecto de capitalismo urbano-industrial orientado al mercado interno. Para alcanzar esta meta, el régimen militar va a diseñar un nuevo modelo de organiza- 
ción académica y de gobierno universitario de carácter vertical, burocrático y autoritario. Este tiene dos bases: los consejos ejecutivos y los departamentos académicos, en cada universidad; y la constitución del llamado sistema de la universidad peruana. En la nueva organización, se reduce o elimina la participación de los estudiantes e, inclusive, de los propios profesores en el gobierno de la universidad, pues se les consideraba como defensores del tradicionalismo universitario y opuesto al cambio. Así, se intentaba imponer una ideología tecnocrática y despolitizada, de acuerdo con la cual los profesores deberían dedicarse únicamente a enseñar y los estudiantes a estudiar.

A pesar de las intenciones tecnocráticas y modernizadoras del proyecto del gobierno militar, la universidad no logró mejorar la calidad de la enseñanza ni supera la ineficiencia administrativa. El desfase entre la universidad y la sociedad se hizo mucho más profundo. Además, la propia institución universitaria estuvo atravesada por mayores conflictos al incrementarse la frustración de estudiantes y de profesores, tanto porque los estudios terminaban generalmente en el desempleo o en subempleo de los primeros, como por el carácter profundamente insatisfactorio en cuanto a las posibilidades de un desarrollo científico y técnico de los segundos.

\section{La contrarreforma neoliberal de la universidad}

El segundo proyecto de reorganización del modelo de universidad de la reforma universitaria se produjo en la década de 1990. El régimen del presidente Fujimori lleva adelante una contrarrevolución neoliberal que reorganiza la economía, la política y la cultura de la sociedad peruana cuya consecuencia fue una creciente reprivatización del poder. La universidad no fue ajena a esas transformaciones. En 1996, el régimen fujimorista promulgó el Decreto Legislativo 882, Ley de promoción de la inversión privada en educación, que posibilita la organización de la universidad - y el conjunto del sistema educativo — con criterios empresariales, donde la finalidad explícita de estas instituciones es la ganancia. Poco a poco los otros tipos de universidad -la universidad pública y la universidad privada sin fines de lucro- también se están orientados según la lógica del mercado.

Entre 1997 y 2012 se crearon 79 universidades (56 privadas y 23 públicas). En la actualidad existen 137 universidades de las cuales 51 son públicas (37 por ciento) y 86 privadas (63 por ciento). De estas universidades, 64 se han creado de acuerdo al DL. 882, esto es, como universidades empresa. La matrícula universitaria también ha crecido explosivamente. En 1990, estaban matriculados 359,778 alumnos y en el 2013, 960,703 alumnos. Además, este crecimiento ha favorecido ampliamente a la universidad privada, en particular a las universidades con fines de lucro. En 1990 había 233,625 matriculados en la universidad pública (65 por ciento) y 126,153 en la 
universidad privada (35 por ciento); para el año 2013, se calcula que en la universidad pública estaban matriculados 327,269 alumnos (34 por ciento) y las privadas 633,437 (66 por ciento).

El modelo neoliberal está redefiniendo la universidad por los menos en dos sentidos. En primer lugar, mediante la mercantilización de los conocimientos -convirtiéndolos en medios para obtener ganancias- y de los profesionales, transformándolos en "capital humano". En el primer caso, la reconversión neoliberal de la universidad se orienta en la dirección de imponer un cambio en el quehacer universitario para insertarla en el capitalismo cognitivo que convierte el conocimiento en una actividad mercantil abandonando los ideales humanistas de la universidad moderna. Esta transformación que toma al mercado como modelo de la educación va a modificar la práctica pedagógica, la investigación y el desenvolvimiento de profesores y estudiantes en la vida universitaria. En el segundo caso, se sostiene el uso instrumental de la enseñanza universitaria según las exigencias de la formación del "capital humano". Nunca como ahora el trabajo es considerado como una mercancía disponible para todo uso, cuya finalidad está determinada por su rentabilidad. Para eso, el profesional debe demostrar que es "empleable". Esta empleabilidad se transforma en la razón de ser del quehacer universitario.

En segundo lugar, se redefine la universidad al mercantilizar la propia institución al convertirla en una empresa orientada a la obtención de ganancias, para lo cual se busca racionalizar los costos al disminuir los pagos a sus asalariados (profesores y empleados) e incrementar los ingresos con las pensiones de los alumnos, a los que considera sus "clientes". Para el capital, se trata de convertir a la universidad en una empresa que permita avanzar en la incesante acumulación de las ganancias. Esta es la lógica del programa neoliberal para la universidad: que la universidad deje de ser un bien público y se convierta en un campo de valorización del capital. Este proyecto implica, de un lado, la creciente disminución de la inversión del estado en la universidad, que se traduce en su crisis financiera; $y$, de otro lado, la mercantilización de la universidad, para lo cual se busca que funcione de manera empresarial. Es la lógica del capital la que busca imponer sus objetivos, su organización y sus prioridades a la institución universitaria. De esta manera, el "mercado de la educación" se ha venido transformando en la panacea del neoliberalismo para resolver los problemas del sistema educativo. La liberalización y la des-reglamentación del sector educativo tienen por efecto la creciente ausencia de los responsables políticos en la toma de decisiones sobre la educación dejando al mercado que determine sobre sus finalidades y sobre su organización. En el caso de la educación superior, los avances en su mercantilización parecen no tener ningún obstáculo y se vienen consolidando rápidamente con la benevolencia y hasta la complicidad del poder político.

Un aspecto característico de la universidad neoliberal es la lógica de la acreditación y, también, la obsesión por los rankings de desempeño de las universidades. Los parámetros y criterios utilizados para determinar la calidad académica de estas evaluaciones 
están determinados por las estructuras de saber/conocer eurocéntricas y son impuestos por aparatos tecnocráticos de evaluación que responden a la lógica del capital y del mercado.

Además, es necesario considerar como la lógica del mercado está destruyendo el sistema de la educación superior y legitimando nuevas formas de división social, en una sociedad cada vez más polarizada, dividida por el "muro del conocimiento". Pues en la era del conocimiento, fundada en recursos inmateriales (saberes, informaciones, comunicación), se instala y crece la separación entre los "calificados" (los que tienen acceso al "conocimiento que cuenta") y los no "calificados" (los excluidos de tal acceso), los que no cuentan, un nuevo subproletariado del capital. La consecuencia perversa de este proceso, por la reducción imparable de la demanda del mercado de trabajo altamente calificado, es el incremento de la desocupación y subocupación entre los profesionales universitarios.

Finalmente, el modelo neoliberal está modificando los valores que han regido la vida universitaria. La educación, en particular la educación universitaria, se ha venido convirtiendo en el campo privilegiado de una cultura individualista; el instrumento clave para triunfar en la era de la competitividad. Más que una cultura de solidaridad, una forma de vivir juntos y con los otros, ha devenido una cultura de la competencia, de la lucha abierta para triunfar sobre los otros. Este individualismo desenfrenado, del cual la corrupción no es más que una de sus consecuencias, está erosionando el tejido social y está poniendo en riesgo nuestra existencia como sociedad.

Para revertir esta perversa orientación neoliberal, la universidad tiene que reorganizarse de manera profunda. La enseñanza y la investigación deben permitir aumentar la libertad, acrecentar la solidaridad, abrir caminos de diálogo y potenciar el respeto de unos seres humanos por otros y por la naturaleza. De este modo, superaremos el falso individualismo reinante y podremos reivindicar la autonomía y la responsabilidad del individuo, uno de los logros mayores de la modernidad, no como proyecto de aislamiento sino de comunidad.

\section{Las opciones sobre el futuro de la universidad}

Dos opciones están emergiendo como alternativas al modelo neoliberal de universidad.

La primera opción es la que propone el modelo neodesarrollista de universidad, y se presenta como la lucha por una Segunda Reforma Universitaria centrada ya no tanto en la democratización del claustro, como fue el planteamiento central de la Reforma de Córdova, sino la elevación de la calidad académica entendida según los criterios del episteme eurocéntrico del conocimiento y una formación profesional de orientación tecnocrática, con lo cual se profundiza y se reactualiza la colonialidad del saber. 
Con la reforma de la universidad se pretende establecer las bases científicas y tecnológicas necesarias para impulsar el desarrollo de un capitalismo nacional centrado en el mercado interno y en la consolidación del país como un Estado nación. En este sentido, el gran desafío que se le plantea a la universidad es el de la investigación y el desarrollo de la ciencia, la tecnología y la innovación. A pesar de los esfuerzos individuales de excelentes investigadores, la universidad en el Perú está muy lejos de alcanzar niveles de investigación de otras universidades latinoamericanas. En la era dominada por la revolución científica y tecnológica, se propone que la universidad necesita, para poder renovarse, ponerse a la vanguardia en algunos ámbitos del trabajo científico donde existen ventajas comparativas y que pueden desarrollarse rápidamente. Este desarrollo permitiría vincularla con las actividades económicas y sociales del país y podría consolidar la propia actividad científica. Además, se considera que la actividad docente debería integrarse de manera indisoluble con la investigación a fin de que la enseńanza se mantenga en el actual nivel del desarrollo alcanzado por las demandas sociales y por el propio desarrollo del conocimiento científico.

La segunda opción es la que está orientada a la descolonialidad de la universidad; esto es, el cuestionamiento radical a la colonialidad/modernidad de la universidad. Se trata de cuestionar a una universidad que desde sus orígenes excluyó tanto a las poblaciones que fueron colonizadas consideradas humanamente inferiores como a sus maneras de conocer y a sus saberes en virtud de la hegemonía de la epistemología eurocéntrica. Este cuestionamiento pasa por tres principios que permitan avanzar hacia la descolonialidad de la universidad: primero, la superación de hegemonía de las estructuras eurocéntricas del saber; segundo, la superación de las estructuras institucionales disciplinarias; y, tercero, por el diálogo entre el saber académico y los saberes de los pueblos subalternizados por colonialidad del poder.

Frente a un sistema educativo homogeneizador y discriminatorio, la descolonialidad de la universidad se presenta como una opción capaz de contribuir a la construcción de una nueva forma de convivencia social donde se eliminen las diversas formas de dominación y de explotación y se respete la diversidad cultural. Considero que la descolonialidad de la universidad constituye una amplia problemática que puede delimitarse alrededor de los vínculos que se establecen con las formas de socialización de las comunidades urbanas y rurales que buscan reproducir en las nuevas generaciones formas comunales de vida en los diversos ámbitos de la existencia social. En ese proceso se van formando mundos subjetivos con las competencias necesarias para hablar y para actuar de la manera socialmente adecuada dentro de esa colectividad, constituyéndose lo que podríamos llamar un hábitus comunitario; esto es la adquisición de los esquemas de "percepción y apreciación" (Bourdieu, 1991: 94) regidos por la solidaridad. La descolonialidad de la universidad tendrá como finalidad el desarrollo de una sociabilidad solidaria. 
La descolonialidad de la universidad requiere un fundamento moral que señale el horizonte hacia donde deberá estar encaminada. Si su núcleo central está dado por la producción y reproducción de las relaciones de solidaridad social, es necesaria la investigación del ordenamiento social al que debe apuntar. Y existen razones suficientes para considerar el buen vivir como el horizonte histórico de futuro al que puede dirigirse.

De manera todavía embrionaria y dispersa se está desarrollándose una tendencia en la sociedad peruana que ambiciona la descolonialidad del poder y que traduce el espíritu del Foro Social Mundial de Porto Alegre. Se trata de un proceso, implicado en el desenvolvimiento milenario de los pueblos indígenas, y de un proyecto que tiene como centro el bien vivir (suma qamaña o sumak kawsay) como horizonte histórico de sentido. Aníbal Quijano lo define con precisión: "un complejo de prácticas sociales orientadas a la producción y a la reproducción democráticas de una sociedad democrática" (Quijano, 2012: 125) Se trata de una racionalidad diferente a la racionalidad instrumental eurocéntrica que se encuentra en la base de la organización de los diferentes ámbitos de las relaciones sociales: la solidaridad entre los seres humanos y la armonía entre los seres humanos con la naturaleza.

La descolonialidad de la universidad implicará la organización de un modelo de universidad intercultural; es decir, el establecimiento de un espacio de saber en dónde dialoguen en igualdad de condiciones las diversas tradiciones culturales, tanto las que han sido hegemónicas en el patrón de poder moderno/colonial, como las perspectivas de conocimiento que habían sido reprimidas o excluidas por este patrón de dominación social. Se trata del principio de la "ecología de saberes" que propone Boaventura de Sousa Santos, el que "consiste en la promoción de diálogos entre el saber científico y humanístico que la universidad produce y los saberes legos, populares, tradicionales, urbanos, campesinos, provincianos, de culturas no occidentales (indígenas de origen africano, oriental, etc.) que circulan en la sociedad" (Santos, 2005: 57)

La descolonialidad de la universidad, además, se vinculará con las experiencias de las diversas formas de trabajo de la economía solidaria. Cuando me refiero a la economía solidaria apunto a un patrón estructural que corresponde a las relaciones de trabajo basadas en la reciprocidad. Se trata de un vasto conjunto de organizaciones económicas que no se estructuran según la lógica de la ganancia y de la acumulación sino en función de la satisfacción de las necesidades colectivas fundamentales. Se puede decir, por tanto, que la lógica en la que se fundan no es la del capital sino la de la reciprocidad o de la comunidad (intercambio de bienes o servicios en la perspectiva de la comunidad).

En conclusión, la descolonialidad de la universidad hace parte importante del proyecto de descolonialidad del patrón de poder moderno/colonial. Constituye un ámbito de disputa del poder de producir e imponer la manera legítima conocimientos y de sentidos sobre la existencia social. Como todas las relaciones de poder, también en el mundo de las relaciones intersubjetivas se producen resistencias. Dependerá de las fuer- 
zas sociales que luchan por un sistema histórico más democrático e igualitario lograr el cuestionamiento de la hegemonía de las estructuras de saber eurocéntrico y de las instituciones en donde se produce y reproduce.

\section{Referencias bibliográficas}

BACHElARD, G. (1972). El nuevo espiritu cientifico, Lima: Universidad Nacional Mayor de San Marcos.

Balandier, G. (1999). El desorden. La teoría del caos y las ciencias sociales. Elogio de la fecundidad del movimiento, Barcelona: Gedisa.

Bourdieu, P. (2003). El oficio de cientifico. Ciencias de la ciencia y reflexividad, Barcelona: Anagrama.

Bowers, C. A. (2002). Detrás de la apariencia. Hacia la descolonización de la educación, Lima: PRATEC.

Castro-Gómez, S. (1998). "Geografías poscoloniales y translocalizaciones narrativas de "lo latinoamericano". La crítica al colonialismo en tiempos de la globalización". En: Follari, Roberto y Lanz Rigoberto (comp.), Enfoques sobre posmodernidad en América Latina, Caracas: Editorial Sentido, 1998. pp. 155-182.

Castro-Gómez, S. (2007). "Decolonizar la universidad. La hybris del punto cero y el diálogo de saberes”. En: Santiago Castro-Gómez y Ramón Grosfoguel (eds.), El giro decolonial. Reflexiones para una diversidad epistémica más allá del capitalismo global, Bogotá: Iesco-Pensar-Siglo del Hombre Editores, pp. 79-91.

Castro-Gómez, S. y Grosfoguel, R. (2007). El giro decolonial. Reflexiones para una diversidad epistémica más allá del capitalismo global, Bogotá: Universidad JaverianaInstituto Pensar / Siglo del Hombre editores.

Castro-Gómez, S. y Grosfoguel, R. (2007). "Prólogo. Giro decolonial, teoría crítica y pensamiento heterónomo", en: S. Castro-Gómez y R. Grosfoguel (eds.), El giro decolonial. Reflexiones para una diversidad epistémica más allá del capitalismo global, Bogotá: Iesco-Pensar-Siglo del Hombre Editores, 2007.

Cerroni, U. (1971). Metodología y ciencia social, Barcelona: Martínez Roca.

Escobar, A. (2003). "Mundos y conocimientos de otro modo. El programa de investigación de modernidad/colonialidad latinoamericano", en: Tabula Rasa, No. 1, Bogotá, pp. 51-86.

Escobar, M. R. (2007). "Universidad, conocimiento y subjetividad. Relaciones de saber/poder en la academia contemporánea”, en Nómadas, Bogotá, N²7, pp. 48-61. Foucault, M. (1981). Las palabras y las cosas. Una arqueología de las ciencias humanas, México: Siglo XXI. 
Foucault, M. (2000). "Clase del 7 de enero de 1976”, en: Defender la sociedad, Buenos Aires: Fondo de Cultura Económica.

González Casanova, P. (2005). Las nuevas ciencias y las humanidades. De la academia a la politica, Barcelona: Anthropos.

LANDER, E. (2000). “¿Conocimiento para qué? ¿Conocimiento para quién? Reflexiones sobre la universidad y la geopolítica de los saberes hegemónicos”, en: Santiago Castro Gómez (ed.), La reestructuración de las ciencias sociales en América Latina, Bogotá: Pontificia Universidad Javeriana.

Mellino, M. (2008). La crítica poscolonial. Descolonización, capitalismo y cosmopolitismo en los estudios poscoloniales, Buenos Aires, Paidós.

Mignolo, W. (2003). Historias locales/diseños globales. Colonialidad, conocimientos subalternos y pensamiento fronterizo, Madrid: Akal.

Nicolis, G. y Portantiero, I. (1997). La estructura de lo complejo. En el camino hacia una nueva comprensión de las ciencias, Madrid: Alianza Editorial.

Palermo, Z. (2005). "La Universidad Latinoamericana en la encrucijada decolonial", Otros Logos. Revista de Estudios críticos, año I, Nro. 1, pp. 43-68.

Portantiero, J. C. (1978). Estudiantes y política en América latina.1918-1938. El proceso de la reforma universitaria, México: Siglo XX.

Prigogine, I. y Stengers, I. (1990). La nueva alianza. Metamorfosis de la ciencia, Madrid: Alianza.

Prigogine, I. (1993). ¿Tan solo una ilusión? Una exploración del caos al orden, Barcelona: Tusquets Editores.

Prigogine, I. (1997). El fin de las certidumbres, Madrid: Taurus.

Prigogine, I. (2004). Las leyes del caos, Barcelona: Crítica.

Putnam, H. (1994). Las mil caras del realismo, Buenos Aires: Paidós.

Quijano, A. (2000a). "Colonialidad del poder, eurocentrismo y América Latina”, en: Edgardo Lander (comp.), Colonialidad del saber: eurocentrismo y ciencias sociales. Perspectivas latinoamericanas, Buenos Aires: Clacso/Unesco, pp. 201-246.

Quijano, A. (2000c). "Colonialidad del poder y clasificación social", en: Journal of World-Systems Research, Vol. VI, No. 2, American Sociological Association, pp. 342-386.

Quijano, A. (2001a). "Colonialidad, poder, cultura y conocimiento en América Latina”, en: Walter Mignolo (comp.), Capitalismo y geopolitica del conocimiento. El eurocentrismo y la filosofía de la liberación en el debate intelectual contemporáneo, Buenos Aires: Signo, pp. 117-131.

Quijano, A. (2001b). "El regreso del futuro y las cuestiones del conocimiento", en: Hueso Húmero, No. 38, Lima, abril, pp. 3-17. 
Quijano, A. (2007). "Don Quijote y los molinos de viento en América Latina", en: Investigaciones Sociales, Año X, No. 16, Lima, Universidad Nacional Mayor de San Marcos - Instituto de Investigaciones histórico sociales, pp. 347-368.

Quijano, A. (2009). "Des/colonialidad del poder: El horizonte alternativo", en: Pasado y Presente, $\mathrm{N}^{\circ} 21$.

Quijano, A. (2010). "Bien vivir" para redistribuir el poder. Los pueblos indígenas y su propuesta alternativa en tiempos de dominación global", en: Oxfam, Pobreza, desigualdad y desarrollo en el Perú. Informe anual 2009-2010.

Quijano, A. (2012). “¿Bien vivir? Entre el "desarrollo” y la descolonialidad del poder”, en M. Daza, R. Hoetmer y V. Vargas (eds.), Crisis y movimientos sociales en nuestra América. Cuerpos, territorios e imaginarios en disputa, Lima: Programa Democracia y Transformación Global, pp. 125-135.

Sader, E., Aboites, H. y Gentile, P. (Compiladores) (2008). La reforma universitaria. Desafios y perspectivas noventa años después, Buenos Aires: CLACSO.

Santos, B. S. (2005). La universidad en el siglo XXI. Para una reforma democrática y emancipadora de la universidad, Buenos Aires: Libros del LPP.

Snow, C. (1977). Las dos culturas y un segundo enfoque, Madrid: Alianza.

Tunnemann, C. (2008). Noventa años de la Reforma Universitaria de Córdova (19182008), Buenos Aires: CLACSO.

Walsh, C. (2001). "¿Qué conocimiento(s)? Reflexiones sobre las políticas de conocimiento, el campo académico, y el movimiento indígena ecuatoriano”, en Pablo Dávalos (comp. y ed.), Yuyarinakuy. Digamos lo que somos, antes que otros nos den diciendo lo que somos, Quito: ICCI/Adya-Yala.

Walsh, C. (2012). Interculturalidad critica y (de)colonialidad. Ensayos desde Abya Yala, Quito: Abya Yala.

Wallerstein, I. (2001). Conocer el mundo, saber el mundo: el fin de lo aprendido. Una ciencia social para el siglo XXI, México: Siglo XXI.

Wallerstein, I. (1997). Abrir las ciencias sociales, México: Siglo XXI.

WallersteIn, I. (1998). Utopística o las opciones históricas del siglo XXI, México: Siglo XXI.

Wallerstein, I. (2005a). Las incertidumbres del saber, Barcelona: Gedisa.

Wallerstein, I. (2005b). Análisis de sistemas-mundo. Una introducción, México: Siglo XXI.

Wallerstein, I. (2007). Universalismo europeo. El discurso del poder, México: Siglo XXI. 